\title{
Meta-Analysis Of Ecological Studies Attenuating Solar Radiation Illustrates The Importance Of Blue Light Over Ultraviolet Radiation In Driving Photodegradation Of Litter In Terrestrial Ecosystems
}

Qing-Wei Wang ( $\nabla$ wangqingwei@iae.ac.cn )

Institute of Applied Ecology https://orcid.org/0000-0002-5169-9881

Marta Pieristè University of Helsinki

Titta K. Kotilainen Natural Resources Institute Finland

\section{Estelle Forey}

Normandie Université

Matthieu Chauvat

Normandie Université

Hiroko Kurokawa

Forestry and Forest Products Research Institute

\section{T Matthew Robson}

University of Helsinki

\section{Alan G Jones}

Forest Systems

\section{Research Article}

Keywords: Biogeochemical cycling, carbon flux, decomposition, litter traits, spectral composition, photodegradation.

Posted Date: March 7th, 2022

DOI: https://doi.org/10.21203/rs.3.rs-1377521/v1

License: (1) (i) This work is licensed under a Creative Commons Attribution 4.0 International License. Read Full License 


\section{Abstract}

Background and aim: Wherever sunlight reaches litter there is potential for photodegradation to contribute to decomposition. Although recent studies have weighted the contribute of the shortwavelength visible spectrum and ultraviolet (UV) radiation as drivers of photodegradation, the relative importance of each spectral region across biomes and plant communities remains uncertain.

Methods: We performed a systematic meta-analysis of studies that assessed photodegradation through spectrally selective attenuation of solar radiation, by synthesizing 30 published studies using field incubations of leaf litter from 110 plant species under ambient sunlight.

Results: Globally, the full spectrum of sunlight significantly increased litter mass loss by $15.3 \% \pm 1 \%$ across all studies compared to darkness. Blue light alone was responsible for most of this increase in mass loss $(13.8 \% \pm 1 \%)$, whereas neither UV radiation nor its individual constituents UV-B and UV-A radiation had significant effects at the global scale, being only important in specific environments. These waveband-dependent effects were modulated by climate and ecosystem type. Among initial litter traits, carbon content, lignin content, lignin to nitrogen ratio and SLA positively correlated with the rate of photodegradation. Global coverage of biomes and spectral regions was uneven across the meta-analysis potentially biasing the results, but also indicating where research in lacking.

Conclusions: Across studies attenuating spectral regions of sunlight, our meta-analysis confirms that photodegradation is a significant driver of decomposition, but this effect is highly dependent on the spectral region considered. Blue light was the predominant driver of photodegradation across biomes rather than UV radiation.

\section{Introduction}

The capability of sunlight to impact litter decomposition in terrestrial ecosystems through the process of photodegradation is by now well established (Bais et al., 2018). Photodegradation involves three main mechanisms: photochemical mineralization, consisting of the direct breakdown of organic matter (Gallo et al., 2006), photofacilitation, meaning the facilitation of microbial decomposition following the photochemical mineralization of complex polymers (Baker \& Allison, 2015), and photoinhibition, referring to the inhibition of microbial decomposition (Barnes et al., 2015). Which of these processes is dominant depends not only on the spectral region considered, but also on other environmental factors, such as temperature and precipitation, interacting with photodegradation (King et al., 2012). In some cases, the positive (photochemical mineralization and consequent photofacilitation) and negative (photoinhibition) effects offset each other (Bais et al., 2018).

Since the 1990s, research into litter photodegradation in terrestrial ecosystems has largely focused on the effects of UV radiation ( $280-400 \mathrm{~nm}$ ), and more specifically UV-B radiation ( $280-315 \mathrm{~nm})$, due to concern about their impact on litter decomposition after the formation of the stratospheric ozone hole (Caldwell \& Flint, 1994; Zepp et al., 1995). Only subsequently were the contributions of other spectral 
regions of sunlight to photodegradation considered (reviewed by King et al., 2012). This research has revealed that short-wavelength regions of the visible spectrum, blue $(400-490 \mathrm{~nm})$ and green $(500-570$ $\mathrm{nm}$ ) light, are also drivers of photodegradation (Austin \& Ballaré, 2010) due to their ability to photochemically degrade lignin (Austin \& Ballaré, 2010; Austin et al., 2016). This process actives decomposer organisms by releasing breakdown produces, potentially releasing a bottleneck in microbial decomposition (Austin et al., 2016). An additional step forward in our understanding of contribution of spectral regions to litter photodegradation was provided by Day \& Bliss, 2019 who devised a polychromatic spectral weighting function for carbon dioxide emission in sunlight from the litter of species from the Sonoran Desert, Arizona. Visible light was found to have $30 \%$ effectiveness and UV-A radiation (315-400 $\mathrm{nm}$ ) to be $61 \%$ effective, making these two spectral regions much more important in photodegradation compared to UV-B radiation (9\%) (Day \& Bliss, 2019).

Photodegradation has a role in litter decomposition in terrestrial ecosystems, not only in arid and semiarid environments at low latitudes (Almagro et al. 2015; Day et al., 2007), as originally thought, but also at higher latitudes (Jones et al., 2016; Zaller et al., 2009) and in mesic environments (Brandt et al., 2010). Recently, forests have been added to the list of ecosystems where photodegradation affects biogeochemical cycling, extending the reach of this process to dynamic radiation environments where gap opening and forest management practices, as well as seasonal phenology, cause large fluctuations in received solar radiation (Méndez et al., 2019; Pieristè et al., 2019, 2020; Wang et al., 2021).

By identifying global trends in the importance and drivers of photodegradation, we can aim to incorporate this knowledge into Earth System Models of the global carbon cycle. Currently, such models handle decomposition based on climatic factors, principally precipitation and temperature and initial litter quality which drive soil organism activities (García-Palacios et al., 2013). However, most studies have produced inconsistent and highly variable results across different environments (Parton et al., 2007). This could be explained by the interaction of photodegradation with other abiotic factors, such as temperature, precipitation and soil moisture, as the relative importance of photodegradation is reported to be enhanced in dryer conditions (Almagro et al., 2017; Brandt et al., 2010; Brandt et al., 2007). Moreover, photodegradation rate increases with those factors that change the exposure of litter to sunlight, such as season, canopy structure and phenological stage, litter layer thickness or litter position (Almagro et al., 2015; Bravo-Oviedo et al., 2017; Henry et al., 2008; Mao et al., 2018; Moody et al., 2001; Rutledge et al., 2010). Additionally, the incident irradiance and spectral composition of solar radiation change with latitude, elevation and sun angle, meaning that underlying patterns of photodegradation should vary consistently across the globe (Aphalo, 2018; Aphalo et al., 2012; Gallo et al., 2009).

Several litter traits were suggested to be good predictors of the photodegradation rate, such as initial lignin content (Austin \& Ballaré, 2010), initial hemicellulose and cellulose (Day et al., 2018; King et al., 2012; Pan et al., 2015). However, there are inconsistencies among studies in the identity of effect traits mediating photodegradation and their hierarchy of importance. This suggests that, while we understand the underlying mechanisms of photodegradation, we are not yet able to account for how it is moderated 
by plant morphological and biochemical traits, and interactions with biotic and abiotic environmental factors.

A quantitative assessment of the literature is required to test whether general trends in photodegradation globally, and the relative importance of different spectral regions, are consistent with expectations gleaned from the recent mechanistic advances identifying the processes underpinning photodegradation. Previously, the effects of UV-B-driven photodegradation were assessed in a meta-analysis by Song et al., 2013 finding UV-B radiation to have no significant, direct or indirect, effects on litter decomposition at the global scale. King et al., 2012 reviewed the effects of UV radiation and visible light below $450 \mathrm{~nm}$, finding that exposure to these spectral regions can increase litter mass loss. However, these two studies (Song et al., 2013) and (King et al., 2012) included both experiments employing supplemental radiation treatments, were produced prior to the majority of studies into visible light, and did not analyse the effect of the separate spectral regions (e.g. UV-B, UV-A, blue light). To date the results from studies on the effects of photodegradation driven by different spectral regions under ambient sunlight, have not been comprehensively synthesised at the global scale. Knowledge of the impact of waveband-dependent photodegradation on litter mass loss across different biomes and plant communities could represent the first step towards quantifying the impact of sunlight on decomposition on a global scale. These estimates will be important because photodegradation is responsible for the release of greenhouse gases, such as methane ( $\mathrm{CH} 4)$, carbon dioxide (CO2) and carbon monoxide (CO), into the atmosphere (Brandt et al., 2009; Day et al., 2019; Schade et al., 1999).

Our objective was to synthesize published studies on the effect of photodegradation driven by UV radiation, its constituent UV-B and UV-A radiation, and blue light on mass loss from litter at the global scale. This would enable us to assess whether the relative importance of these spectral regions globally is consistent with the mechanistic advancements in our understanding of these processes. Moreover, we assess whether photodegradation rates are modulated by climate, ecosystem type, length of the exposure period and litter habit (evergreen or deciduous), as well as litter traits. We expect blue light- and UV-A radiation-driven photodegradation to enhance litter mass loss, due to the ability of these spectral regions to degrade lignin (Austin \& Ballaré, 2010) Moreover, we expect photodegradation to be more relevant (1) in arid than mesic conditions, where precipitation is likely to be the main driver of the decomposition process (Bais et al., 2018), as well as (2) in ecosystems with low canopy cover which allow most of the incident solar radiation to penetrate to the litter layer.

\section{Material And Methods}

\section{Data collection}

Data for the meta-analysis were extracted from literature published between 1980 and January 2021, collected from Web of Science, Google Scholar, and Scopus database (Details of the keywords used are shown in Online Resource 1). We selected only studies that spectrally selectively attenuated solar radiation to measure the photodegradation of surface leaf litter in terrestrial ecosystems. We excluded 
any studies that did not separate single wavebands or that did not allow the effect of single wavebands to be calculated due to the lack of a control treatment. Since one of our aims was to understand the effects of spectral composition on mass loss under ambient sunlight, all studies employing supplemental radiation were excluded. Moreover, as we aimed to examine the correlation between photodegradation rate and litter traits, we retained only studies employing leaf litter from a single species, while we excluded studies using litter mixtures (More details about study selection are found Online Resource 1). We considered dark treatments to be only treatments blocking more than $95 \%$ of the solar spectrum. We extracted data concerning litter mass loss and initial litter traits. Where data were not presented in tables, we extracted them directly from the figures using WebPlotDigitizer 4.2 (Rohatgi, 2019). We retained a total of 30 articles (The list of retained studies is shown in Online Resource 2) which produced a total of 325 datapoints. Several papers included comparisons of multiple plant species (A list of the 114 species included is shown in Online Resource 3), field sites and spectral treatments. The effects of five spectral regions were calculated: 1) UV radiation (280-400 nm); 2) UV-B radiation (280-315 nm); 3) UV-A radiation $(315-400 \mathrm{~nm}) ; 4)$ blue light $(400-490 \mathrm{~nm})$ and 5) the full spectrum of visible light and UV radiation. The effect of each spectral region was obtained by comparison of pairs of spectral treatments applied in the original studies: the effects of excluding UV radiation, UV-B radiation and the full-spectrum were obtained by comparison of the control treatment with the no-UV, no-UVB and dark respectively; while the effect of UV-A radiation was obtained by comparison between the no-UV and the no-UVB treatment and the effect of blue light by contrasting the no-UV/blue and no-UV treatments as in (Wang et al., 2020). There were too few studies to be able to test the effects of green light.

Additionally, we extracted complementary information from each study: ecosystem (grassland, shrubland, woodland and open area); length of the decay period (the duration of the experiment in months); habit (evergreen or deciduous); litter form (herbaceous; shrub, tree); latitude (details about the categorisation of these data and complementary information are shown in Online Resource 4 and in the dataset (Pieristè et al., 2021). The climate at each study site was defined according to the updated Koppen-Geiger climate classification using the map provided by (Beck et al., 2018), which divides the globe into five major climatic zones further separated into subdivisions based on temperature and precipitation (Details of the climate classification are shown in Online Resource 5).

In order to deliver estimate global-scale quantities of $C$ released from surface litter by photodegradation, we extracted data from the Soil Respiration Data Base (SRDB) database (Bond-Lamberty \& Thomson, 2010) on the annual litter carbon flux from each of the biomes corresponding to the location of studies in the meta-analysis. These data allowed us to roughly estimate the carbon flux in each of these biomes attributable to litter mass loss due to photodegradation. Identification of the biomes was based on the WWF biomes classification (Olson et al., 2001).

\section{Statistical analysis}

The effect sizes, expressed as log response ratio (InRR) of mass loss, were computed with the function escalc() from the package 'metafor' (ver. 2.1-0) (Viechtbauer, 2019), which uses sample sizes, standard deviations and means of the original studies and presents bias correction for small sampling. For each 
study, we selected only the final collection date to avoid the potential issue of time-dependent effect sizes. We used a three-level mixed effect model using study ID and effect size ID as random factors as described in (Assink \& Wibbelink, 2016), with categorical variables "Ecosystem”, “Decay”, "Climate”, "Habit", "Life form" and "Latitude" as fixed factors. The use of multilevel modelling in meta-analyses is a robust method for dealing with the problem of dependent effect sizes (Assink \& Wibbelink, 2016; Cheung, 2014; Noortgate et al., 2013). We used this method to test the overall effect of exclusion of each spectral region and the effect of the categorical variables with the function rma.mv() from the package 'metafor' (ver. 2.1-0) (Viechtbauer, 2019), employing the Knapp and Hartung correction method for random metaanalyses (Assink \& Wibbelink, 2016; Knapp \& Hartung, 2003). From these models we obtained the estimated average InRR which we used to calculate the percentage change to better interpret the magnitude effect with the formula from Pustejovsky, 2018.

Following the same multi-level approach, we analysed the correlation between the rate of photodegradation (effect size $=\operatorname{lnRR}$ ) and the initial litter traits, climatic variables during the study period and absolute latitude, using them as continuous moderators in the model. The litter traits considered were those initial traits reported in each study: carbon content $(\mathrm{C})$; nitrogen content $(\mathrm{N})$; carbon to nitrogen ratio (C:N); lignin content; lignin to nitrogen ratio (Lig: $\mathrm{N})$ and specific leaf area (SLA). The climatic variables used were average (Tmean), minimum (Tmin) and maximum temperature (Tmax), and cumulative precipitation (PP), over the study period. These data were obtained from the NASA Langley Research Center POWER Project funded through the NASA Earth Science Directorate Applied Science Program (Sparks, 2018) using the "nasapower" R package version 3.0.1 (Sparks, 2020).

The paucity of published studies from certain climates, ecosystems, latitude, etc. has the potential to introduce bias into the meta-analysis. To assess the risk of bias, we explored the dataset of retained studies to identify over- and under-represented categories. To evaluate literature bias we employed an Egger's test (Egger et al., 1997) which uses the variance of the effect size as a moderator of a multi-level meta-analysis (Viechtbauer, 2010), this allowed us to account for dependency among the effect sizes.

\section{Results}

\section{Effect of full-spectrum-driven photodegradation on litter mass loss}

The full-spectrum of sunlight compared to a control in darkness significantly increased litter mass loss overall $(+15.3 \% \pm 1 \%, p=0.040, n=76$, Fig. $2 a$, Table 1$)$, however, this effect varied significantly depending on climate $(p=0.001$, Table 2$)$, ecosystem type $(p<0.001$, Table 2$)$, decay period $(p<0.001$, Table 2$)$ and life form of the litter $(p=0.020$, Table 2$)$. Specifically, only in dry $(+36.3 \%, p<0.001$, Fig. $2 a)$ and temperate climates $(+18.6 \%, p=0.026$, Fig. $2 a)$ did the full spectrum significantly increase mass loss. In terms of ecosystem type, the full-spectrum of sunlight increased mass loss only in open areas (+ $40.8 \%, p=0.026$, Fig. 2a) and shrublands $(+36.3 \%, p<0.001$, Fig. $2 a)$, while it had no significant effect in grasslands ( $p=0.191$, Fig. 2a) or woodlands ( $p=0.131$, Fig. 2a). Furthermore, the full spectrum of 
sunlight significantly increased litter mass loss in studies that lasted six to twelve months $(+34 \%, p<$ 0.001 , Fig. 2a), but it had no significant effect across studies that lasted less than six months $(p=0.219$, Fig. 2a) nor more than twelve months ( $p=0.420$, Fig. $2 a$ ). In terms of life form, the full-spectrum of sunlight increased mass loss only of shrub litter $(+20.1 \%, p=0.014$, Fig. $2 a)$.

Table 1

Overall estimated log response ratio (InRR) of mass loss, 95\% confidence interval and $p$-value for each spectral region. Values in bold indicate statisticalsignificance. $\mathrm{n}$ indicates the number of replicates.

\begin{tabular}{|lllllll|}
\hline Spectral region & $\mathbf{n}$ & Estimate & $\mathbf{9 5 \%} \mathbf{C l}$ & & $p$-value & \% change \\
\hline Full-spectrum & $\mathbf{7 6}$ & $\mathbf{0 . 1 4 2}$ & $\mathbf{0 . 0 0 7}$ & $\mathbf{0 . 2 7 6 8}$ & $\mathbf{0 . 0 4 0}$ & $\mathbf{1 5 . 2 6}$ \\
\hline Blue light & $\mathbf{5 1}$ & $\mathbf{0 . 1 2 9}$ & $\mathbf{0 . 0 0 9}$ & $\mathbf{0 . 2 4 9}$ & $\mathbf{0 . 0 3 5}$ & $\mathbf{1 3 . 7 7}$ \\
\hline UV-A radiation & 34 & -0.014 & -0.070 & 0.041 & 0.606 & -1.39 \\
\hline UV-B radiation & 44 & 0.012 & -0.071 & 0.096 & 0.770 & 1.21 \\
\hline UV radiation & 118 & 0.069 & -0.091 & 0.228 & 0.397 & 7.14 \\
\hline
\end{tabular}


Table 2

Heterogeneity between groups $(\mathrm{Qb})$ and $p$-values of the moderators for each spectral region. Values in bold indicate statistical-significance.

\begin{tabular}{|c|c|c|c|}
\hline Spectral region & Variable & Qb & $p$-value \\
\hline \multirow[t]{5}{*}{ Full-spectrum } & Climate & 5.82 & 0.001 \\
\hline & Decay period & 8.72 & $<0.001$ \\
\hline & Ecosystem & 9.7 & $<0.001$ \\
\hline & Habit & 0.71 & 0.405 \\
\hline & Life form & 4.14 & 0.02 \\
\hline \multirow[t]{5}{*}{ Blue } & Climate & 4.73 & 0.013 \\
\hline & Decay period & 0.54 & 0.586 \\
\hline & Ecosystem & 38.51 & $<0.001$ \\
\hline & Habit & 0.06 & 0.801 \\
\hline & Life form & 0.34 & 0.711 \\
\hline \multirow[t]{5}{*}{ UV- A } & Climate & 1.05 & 0.312 \\
\hline & Decay period & 1.25 & 0.301 \\
\hline & Ecosystem & 1.44 & 0.252 \\
\hline & Habit & 0.96 & 0.338 \\
\hline & Life form & 0.13 & 0.879 \\
\hline \multirow[t]{5}{*}{ UV- B } & Climate & 8.77 & $<0.001$ \\
\hline & Decay period & 2.19 & 0.124 \\
\hline & Ecosystem & 2.19 & 0.103 \\
\hline & Habit & 4.43 & 0.044 \\
\hline & Life form & 2.03 & 0.145 \\
\hline \multirow[t]{5}{*}{ UV } & Climate & 0.02 & 0.979 \\
\hline & Decay period & 2.76 & 0.031 \\
\hline & Ecosystem & 2.31 & 0.08 \\
\hline & Habit & 0.44 & 0.51 \\
\hline & Life form & 1.87 & 0.158 \\
\hline
\end{tabular}




\section{Effect of blue light-driven photodegradation on litter mass loss}

Blue light caused an increase in mass loss overall $(+13.8 \% \pm 1 \%, p=0.035, \mathrm{n}=51$, Fig. 2b, Table 1$)$ and this effect was dependent on climate $(p=0.013$, Table 2$)$ and ecosystem type $(p<0.001$, Table 2$)$. Blue light significantly increased litter mass loss only in dry climates $(+9 \%, p<0.001$, Fig. $2 \mathrm{~b})$ but had a marginally non-significant effect on litter mass loss in temperate climates $(p=0.052$, Fig. $2 b)$ and a no significant effect in continental climates ( $p=0.782$, Fig. 2b). Moreover, blue light significantly increased litter mass loss in open areas $(+64 \%, p<0.001$, Fig. $2 b)$ and shrublands $(+9 \%, p<0.001$, Fig. $2 b)$, but not in woodlands ( $p=0.254$, Fig. $2 b$ ).

\section{Effect of UV-driven photodegradation on litter mass loss}

UV radiation had no significant effect on mass loss overall ( $p=0.397, \mathrm{n}=118$, Fig. 2e, Table 1$)$. However, there was a significant interactive effect of UV radiation modulated by the decay period $(p=0.031$, Table 2), whereby in studies shorter than 3 months and longer than 24 months UV radiation increased mass loss by $43.7 \%(p<0.001$, Fig. $2 c)$ and $33.2 \%$ respectively ( $p=0.031$, Fig. $2 c)$. The UV-B spectral region within UV radiation, likewise did not have a significant overall effect on litter mass loss $(p=0.770$, $\mathrm{n}=45$, Fig. 2d, Table 1). However, the effect of UV-B radiation changed according to climate $(p<0.001$, Table 2$)$ and habit $(p=0.044$, Table 2$)$. UV-B radiation significantly increased mass loss in dry $(+13.1 \%, p$ $=0.007$, Fig. $2 \mathrm{~d})$ and temperate climates $(+6.4 \%, p=0.006$, Fig. $2 \mathrm{~d}$ ), while it reduced mass loss in polar climates $(-20.9 \%, p=0.020$, Fig. $2 d)$. Moreover, UV-B radiation increased mass loss from the litter of both deciduous $(+6.3 \%, p=0.018$, Fig. $2 \mathrm{~d}$ ) and evergreen $(+20.6 \%, p=0.012$, Fig. $2 \mathrm{~d})$ shrubs and trees. We did not find a significant effect of UV-A radiation on mass loss overall $(p=0.606, \mathrm{n}=34$, Fig. 2e, Table 1$)$.

\section{The relationship between photodegradation and abiotic factors}

Photodegradation driven by the full-spectrum of sunlight was moderated by $\operatorname{Tmax}\left(0.011 ; t_{(74)}=-2.524, p\right.$ $=0.014$, Table 3$)$. Photodegradation attributable to blue light was significantly moderated by:

precipitation $\left(0.001 ; t_{(51)}=2.887, p=0.006\right.$, Table 3$)$ and $\operatorname{Tmin}\left(0.014 ; t_{(51)}=3.392, p=0.001\right.$, Table 3$)$. On the other hand, photodegradation attributable to the UV-B radiation was significantly moderated by:

Tmean $\left(0.017 ; t_{(44)}=4.461, p<0.001\right.$, Table 3), $\operatorname{Tmax}\left(0.013 ; t_{(44)}=4.582, p<0.001\right.$, Table 3$)$ and absolute latitude $\left(-0.006 ; t_{(44)}=-2.313, p=0.006\right.$, Table 3$)$. 
Table 3

Number of replicates $(\mathrm{n})$, regression coefficient $(\beta), t$-value and $p$-value obtained from the three-level meta-analysis including initial litter traits, climatic variables and absolute latitude as continuous moderators. Initial litter traits are: carbon content $(\mathrm{C})$, nitrogen content $(\mathrm{N})$, carbon to nitrogen ratio (C:N), lignin content, lignin to nitrogen ratio (Lig: $\mathrm{N}$ ) and specific leaf area

(SLA). Climatic variables are: cumulative precipitation in $\mathrm{mm}$ (PP), average temperature in ${ }^{\circ} \mathrm{C}$ (Tmean), minimum temperature in ${ }^{\circ} \mathrm{C}(\mathrm{Tmin})$ and maximum temperature in ${ }^{\circ} \mathrm{C}$ (Tmax). The latitude represents absolute latitude. Values in bold indicate statistical-significance.

\begin{tabular}{|c|c|c|c|c|c|}
\hline Spectral region & Variable & $\mathrm{n}$ & $\beta$ & $t$ value & $p$-value \\
\hline \multirow[t]{11}{*}{ Full-spectrum } & $\mathrm{C}$ & 67 & $0.025 \pm 0.006$ & 3.964 & $<0.001$ \\
\hline & $\mathrm{N}$ & 67 & $-0.020 \pm 0.078$ & -0.251 & 0.803 \\
\hline & C:N & 67 & $0.004 \pm 0.003$ & 1.179 & 0.243 \\
\hline & Lignin & 47 & $0.007 \pm 0.005$ & 1.527 & 0.134 \\
\hline & Lig:N & 47 & $0.008 \pm 0.006$ & 1.298 & 0.201 \\
\hline & SLA & 67 & $-0.001 \pm 0.001$ & -0.659 & 0.512 \\
\hline & Latitude & 76 & $0.003 \pm 0.008$ & 0.443 & 0.659 \\
\hline & PP & 76 & $-0.001 \pm 0.000$ & -1.139 & 0.258 \\
\hline & Tmean & 76 & $0.001 \pm 0.010$ & 0.109 & 0.914 \\
\hline & Tmin & 76 & $-0.011 \pm 0.007$ & 1.686 & 0.096 \\
\hline & Tmax & 76 & $0.011 \pm 0.004$ & 2.524 & 0.014 \\
\hline \multirow[t]{11}{*}{ Blue } & C & 43 & $0.023 \pm 0.013$ & 1.835 & 0.074 \\
\hline & $\mathrm{N}$ & 43 & $-0.097 \pm 0.056$ & -1.650 & 0.107 \\
\hline & $\mathrm{C}: \mathrm{N}$ & 43 & $0.004 \pm 0.004$ & 1.714 & 0.094 \\
\hline & Lignin & 36 & $0.017 \pm 0.007$ & 2.455 & 0.019 \\
\hline & Lig:N & 36 & $0.016 \pm 0.006$ & 2.666 & 0.012 \\
\hline & SLA & 51 & $0.001 \pm 0.000$ & 2.726 & 0.009 \\
\hline & Latitude & 51 & $-0.007 \pm 0.004$ & -1.656 & 0.104 \\
\hline & PP & 51 & $0.001 \pm 0.000$ & 2.887 & 0.006 \\
\hline & Tmean & 51 & $0.009 \pm 0.005$ & 1.746 & 0.087 \\
\hline & Tmin & 51 & $0.014 \pm 0.004$ & 3.392 & 0.001 \\
\hline & Tmax & 51 & $0.004 \pm 0.004$ & 0.849 & 0.4 \\
\hline UV-A & $\mathrm{C}$ & 33 & $-0.001 \pm 0.010$ & -0.118 & 0.907 \\
\hline
\end{tabular}




\begin{tabular}{|c|c|c|c|c|c|}
\hline Spectral region & Variable & $\mathbf{n}$ & $\beta$ & $t$-value & $p$-value \\
\hline & $\mathrm{N}$ & 33 & $-0.053 \pm 0.059$ & -0.901 & 0.374 \\
\hline & C:N & 33 & $0.002 \pm 0.002$ & 1.352 & 0.186 \\
\hline & Lignin & 26 & $-0.007 \pm 0.008$ & -0.788 & 0.439 \\
\hline & Lig:N & 26 & $0.003 \pm 0.006$ & 0.546 & 0.59 \\
\hline & SLA & 31 & $0.001 \pm 0.001$ & 0.372 & 0.713 \\
\hline & Latitude & 34 & $0.002 \pm 0.005$ & 0.376 & 0.709 \\
\hline & PP & 34 & $-0.000 \pm 0.000$ & -0.060 & 0.953 \\
\hline & Tmean & 34 & $0.002 \pm 0.009$ & 0.159 & 0.875 \\
\hline & Tmin & 34 & $0.004 \pm 0.006$ & 0.677 & 0.503 \\
\hline & Tmax & 34 & $-0.007 \pm 0.009$ & -0.755 & 0.456 \\
\hline \multirow[t]{11}{*}{ UV-B } & C & 36 & $0.017 \pm 0.005$ & 3.527 & 0.001 \\
\hline & $N$ & 36 & $-0.035 \pm 0.041$ & -0.847 & 0.403 \\
\hline & $\mathrm{C}: \mathrm{N}$ & 40 & $0.002 \pm 0.001$ & 1.663 & 0.105 \\
\hline & Lignin & 31 & $0.006 \pm 0.004$ & 1.695 & 0.101 \\
\hline & Lig:N & 29 & $0.008 \pm 0.004$ & 2.156 & 0.04 \\
\hline & SLA & 31 & $-0.000 \pm 0.000$ & 0.610 & 0.547 \\
\hline & Latitude & 44 & $-0.006 \pm 0.003$ & -2.313 & 0.026 \\
\hline & PP & 44 & $0.000 \pm 0.000$ & 1.759 & 0.086 \\
\hline & Tmean & 44 & $0.017 \pm 0.004$ & 4.461 & $<0.001$ \\
\hline & Tmin & 44 & $0.002 \pm 0.007$ & 0.259 & 0.797 \\
\hline & Tmax & 44 & $0.013 \pm 0.003$ & 4.582 & $<0.001$ \\
\hline \multirow[t]{7}{*}{ UV } & $\mathrm{C}$ & 76 & $0.017 \pm 0.007$ & 2.386 & 0.02 \\
\hline & $\mathrm{N}$ & 78 & $-0.048 \pm 0.047$ & -1.021 & 0.311 \\
\hline & $\mathrm{C}: \mathrm{N}$ & 78 & $0.001 \pm 0.001$ & 1.087 & 0.281 \\
\hline & Lignin & 84 & $-0.002 \pm 0.005$ & -0.375 & 0.709 \\
\hline & Lig:N & 61 & $0.001 \pm 0.003$ & 0.344 & 0.732 \\
\hline & SLA & 82 & $-0.001 \pm 0.000$ & -1.906 & 0.06 \\
\hline & Latitude & 118 & $0.003 \pm 0.008$ & 0.356 & 0.723 \\
\hline
\end{tabular}




\begin{tabular}{|llllll|}
\hline Spectral region & Variable & $\mathbf{n}$ & $\boldsymbol{\beta}$ & $\boldsymbol{t}$-value & $\boldsymbol{p}$-value \\
& $\mathrm{PP}$ & 118 & $0.001 \pm 0.000$ & 1.035 & 0.303 \\
& $\mathrm{Tmean}$ & 118 & $-0.010 \pm 0.012$ & -0.874 & 0.384 \\
& $\mathrm{Tmin}$ & 118 & $-0.007 \pm 0.005$ & -1.231 & 0.221 \\
& $\mathrm{Tmax}$ & 118 & $0.016 \pm 0.008$ & 1.946 & 0.054 \\
\hline
\end{tabular}

\section{The relationship between Initial litter traits and photodegradation}

Photodegradation driven by the full-spectrum of sunlight was moderated by initial $C$ content $\left(0.025 ; t_{(67)}\right.$ $=3.964, p<0.001$, Table 3$)$. The same was true for photodegradation driven by UV-B radiation $\left(0.017 ; t_{(36)}\right.$ $=3.527, p=0.001$, Table 3$)$ and UV radiation $\left(0.017 ; t_{(76)}=2.386, p=0.020\right.$, Table 3$)$. In addition, photodegradation driven by UV-B was moderated by Lig:N $\left(0.008 ; t_{(29)}=2.156, p=0.040\right.$, Table 3). Photodegradation attributable to blue light was significantly moderated by: initial lignin content $(0.017$; $t_{(36)}=2.455, p=0.019$, Table 3); Lig: $\mathrm{N}\left(0.016 ; t_{(36)}=2.666, p=0.012\right.$, Table 3) and SLA $\left(0.001 ; t_{(51)}=2.726\right.$, $p=0.009$, Table 3 ).

\section{Bias analysis and bias exploration}

We did not find bias in any of the datasets used to calculate the effect of each spectral region: fullspectrum $\left(\mathrm{F}_{1,74}=0.265, p\right.$-value $\left.=0.608\right)$; blue light $\left(\mathrm{F}_{1,49}=0.336, p\right.$-value $\left.=0.565\right)$; $\mathrm{UV}$-A radiation $\left(\mathrm{F}_{1,32}=\right.$ $0.226, p$-value $=0.638)$; UV-B radiation $\left(F_{1,43}=0.03, p\right.$-value $\left.=0.857\right)$ and $U V$ radiation $\left(F_{1,116}=0.345, p\right.$ value $=0.558)$. UV radiation was the most studied spectral region (20 studies, $n=118)$, while blue light (5 studies, $n=51$ ) and UV-A radiation ( 5 studies, $n=34$ ) were under-represented in our dataset (Fig. $1 \mathrm{a}$ ). Most studies were carried out at latitudes between $30^{\circ}$ and $50^{\circ}$ North and South, while data from high latitudes were lacking (Fig. 1b). Grassland and shrubland ecosystems were more studied than woodlands and open areas (Fig. 1c). Dry climates were the most studied, while polar and tropical climates were the least studied (Fig. 1d). In terms of the decay period, the first 12 months of decomposition were the most studied (Fig. 1e). The studies were located in six biomes: "boreal forests/taiga", "deserts and xeric shrublands", "Mediterranean forests, woodlands and scrub", "montane grasslands and shrublands", "temperate broadleaf and mixed forests", "temperate grasslands, savannas and shrublands" and "tropical and subtropical moist broadleaf forests" (Figs. 1 and 3 and further details are shown in Online Resource 6).

\section{Discussion}

\section{The relative importance of blue light and UV radiation in global photodegradation}


Exposure to the full-spectrum of sunlight increased litter mass loss by $15.3 \% \pm 1 \%$ overall (Table 1 , Fig. 2a), confirming that sunlight is among the suite of abiotic factors driving decomposition across the globe. This result is in agreement with previous findings analysing the effect of the full-spectrum of sunlight on litter mass loss (Day et al., 2015; Ma et al., 2017; Pan et al., 2015). However, the magnitude of the effect is smaller than that found in an earlier meta-analysis (King et al., 2012), which calculated an increase in mass loss of $23 \%$ due to sunlight. Our meta-analysis includes studies that were carried out in temperate and hemi-boreal forest environments (Pieristè et al., 2019, 2020; Wang et al., 2021); ecosystems that were not represented in the meta-analysis by King et al., 2012. In temperate and boreal forests, sunlight tends to have the opposite net effect on photodegradation compared with forests at lower latitudes (Ma et al., 2017), actually decreasing litter mass loss in some litter species (Pieristè et al., $2019,2020)$. Hence, the inclusion of studies from these biomes may explain the lower net contribution of photodegradation to decomposition on the global scale that we report.

Comparing spectral regions, blue light explained most of the mass loss attributable to solar radiation globally (a 13.8\% $\pm 1 \%$ increase in decomposition due to blue light; Table 1, Fig. $2 b$ ); while UV, UV-A and UV-B radiation had no significant effect on litter mass loss globally. This is in agreement with a previous meta-analysis showing no overall effect of UV-B radiation (Song et al., 2013). The high energetic capacity of UV radiation to cause oxidative stress in living organisms has the potential to slow down microbial decomposition, as reported in several studies (Moody et al., 1999; Moody et al., 2001; Verhoef et al., 2000), although this photoinhibition may sometimes be offset by direct photochemical mineralization (Gallo et al., 2009). These two antagonistic processes can lead the effects of UV and UV-B radiation to differ across biomes with climate according to the importance of microbial decomposition: for example, decomposition is increased by UV and UV-B radiation in arid and semiarid climates but this effect does not extend to temperate and continental climates (Gallo et al., 2006, 2009; Pieristè et al., 2019, 2020). On the other hand, blue light is effective in causing photochemical mineralization, but appears not to produce photoinhibition (Austin et al., 2016); this is likely to be the reason why the global positive effect of blue light on litter decomposition is distinct from the inconsistent effect of UV radiation globally. Although the composition of spectral irradiance changes with latitude, elevation, canopy cover and topology, the energetic contribution of blue light always remains greater than that of UV radiation (Aphalo et al., 2012). The recent spectral weighting function for the emission of $\mathrm{CO}_{2}$ through photodegradation illustrates the action of sunlight on decomposing litter (Day \& Bliss, 2019) and its consistency with the results of this global meta-analysis for sunlight and blue light supports the use of this action spectrum when up-scaling across ecosystems. However, unlike Day \& Bliss, 2019 we did not identify UV-A radiation as the most effective spectral region driving carbon emission through photodegradation across all studies in our meta-analysis. This could be due to the fact that most studies testing the effect of UV-A radiation were located in cool moist temperate broadleaf forest biomes at high latitudes characterised by low UV-A radiation (Aphalo et al., 2012; Grifoni et al., 2008).

We estimated annual carbon flux from litter attributable to photodegradation driven by different spectral regions, applying the percentage contributed by photodegradation to the gross annual carbon flux lost 
from litter in each biome obtained from the SRDB dataset (Bond-Lamberty \& Thomson, 2010). This produced an estimate of photodegradation driven by the full spectrum of sunlight of up to $5-61 \mathrm{~g} \mathrm{C} \mathrm{m}^{-2}$ per year according to biome type (Table 4), while blue light would potentially be responsible for 4-55 g C $\mathrm{m}^{-2}$ per year according to biome type (Table 4). Scaling up these estimates to a global scale, photodegradation due to the full spectrum of sunlight would contribute 1.95 Pg to the annual global terrestrial carbon flux over the six biomes studied, with each biome responsible for carbon emissions of between $0.02-0.92 \mathrm{Pg}$. We would like to remind the reader that this estimate is only based on upscaling the carbon flux data from studies of those biomes included in our meta-analysis and don't constitute a comprehensive global estimate. These figures are just indicative of the magnitude of the potential impact of photodegradation at the global scale. These estimates are greater than those from an existing modelling study (Foereid et al., 2011) which found photodegradation not to have a significant impact on the global $\mathrm{C}$ budget. However, at the time of that modelling study (Foereid et al., 2011), no data were available for high latitudes and forest ecosystems. There is the need for updated global modelling studies that incorporate the recent conceptual advances in our knowledge of photodegradation at the mechanistic level and cover a broader diversity of environments.

\section{Table 4}

Average carbon flux in $\mathrm{g} \mathrm{C} \mathrm{m}^{-2}$ and corresponding standard error (SE) attributable to photodegradation in each biome divided according to spectral regions. Contribution to carbon emission (+) and retention (-). However, data for the tropical and subtropical biome were not available ("na").

\begin{tabular}{|lllll|}
\hline Biome & \multicolumn{2}{c}{ Full-spectrum } & \multicolumn{2}{c|}{ Blue light } \\
\cline { 2 - 5 } & Average & SE & Average & SE \\
\hline Boreal forests / Taiga & 61.05 & 23.52 & 55.09 & 21.23 \\
\hline Deserts and xeric shrublands & 14.13 & 3.92 & 12.75 & 3.54 \\
\hline Mediterranean forests, woodlands and scrub & 7.32 & 0 & 6.61 & 0 \\
\hline Montane grasslands and shrublands & 20.2 & 10.94 & 18.23 & 9.87 \\
\hline Temperate broadleaf and mixed forests & 35.07 & 2.39 & 31.65 & 2.15 \\
\hline Temperate grasslands, savannas and shrublands & 5.46 & 3.36 & 4.93 & 3.03 \\
\hline Tropical and subtropical moist broadleaf forests & na & na & na & na \\
\hline
\end{tabular}

Climate moderated photodegradation driven by blue light, UV-B radiation and the full-spectrum of sunlight, with the highest photodegradation rates occurring in dry climates. These results support the theory that dry climatic conditions tend to promote photodegradation, where it is often the most important driver of decomposition when microbial activity is strongly reduced (Brandt et al., 2007; Gallo et al., 2006). On the contrary, in temperate and continental climates decomposition is likely to be driven by factors promoting biotic processes, such as precipitation and temperature cycles (Adair et al., 2008; Aerts, 
1997; Meentemeyer, 1978). Nevertheless, we did not find a global correlation between cumulative precipitation and photodegradation driven by the full-spectrum of sunlight and UV radiation. This could be due to the fact that precipitation does not include other forms of moisture (e.g. fog and dew) known to be involved in photofacilitation (Gliksman et al., 2017). On the other hand, the precipitation was positively correlated with blue light photodegradation globally. This may suggest that blue light is involved in facilitating microbial decomposition (photofacilitation) in moist ecosystems, as previously proposed by Gliksman et al., 2017 and Pieristè et al., 2020.

In addition, we found that full-spectrum and UV-B photodegradation, were positively correlated with both the maximum and average temperature. This is in agreement with the trend reported for a Mediterranean grassland (Almagro et al., 2015). This relationship suggests that under warmer conditions, which increase evaporative demand and may consequently reduce in litter moisture (Maestre et al., 2013), the relative importance of photodegradation may increase due to slower microbial decomposition (Almagro et al., 2015, 2017; Bais et al., 2018).

\section{Initial litter traits as predictors of photodegradation rate at the global scale}

In our meta-analysis, initial lignin content and initial Lig:N positively correlated with the rates of blue-light and UV-B photodegradation (Table 3). This result reaffirms the primary role of lignin in the process of photodegradation as a primary target of photochemical mineralization due to its capacity to absorb blue light and UV radiation (Austin \& Ballaré, 2010). The importance of this process has been well established for dry climates, but the meta-analysis extends this pattern to temperate and continental climates as well as ecosystems characterised by high canopy cover, where litter typically receives low irradiance depleted in blue light (Pieristè, 2020). Moreover, these results highlight the greater importance of photodegradation in the decomposition of recalcitrant litter compared to labile litter (King et al., 2012; Pieristè et al., 2019). Recalcitrant litter is characterised by high Lig: $\mathrm{N}$ and high lignin content. This complex carbon macromolecule is not directly available to microbial decomposers before photofacilitation (Austin et al., 2016). Initial hemicellulose and cellulose content have also been proposed as potential targets of photodegradation (Day et al., 2018; Lin et al., 2015). Unfortunately, few studies have measured these traits, so we could not test this hypothesis in our meta-analysis.

\section{Potential bias and further considerations}

Every meta-analysis is subjected to bias, for this reason results must be interpreted with care. Exploring the literature published about photodegradation under ambient sunlight, we identified some over- and under-represented categories that could potentially affect our results. For instance, UV-driven photodegradation is the most studied, while relatively little attention has focused on blue and green light, as their importance in driving photodegradation was revealed relatively recently (Austin et al., 2016). We might expect that as more studies focus on these under-represented spectral regions, our results would change. Moreover, studies of photodegradation were mainly located at latitudes between $30^{\circ}$ and $50^{\circ}$ North and South (Fig. 1b), with equatorial and high latitudes being under-represented. As 
photodegradation has even proved relevant even under relatively low irradiances (Pieristè et al., 2019, 2020), the study of photodegradation in biomes at high latitudes and with a dynamic vegetation structure will be necessary to understand the real impact of photodegradation at the global scale. Moreover, woodlands are by far less studied than shrublands and grasslands and these studies are located at higher latitudes in temperate and continental climates, while grasslands have mainly been studied in arid and semiarid climates at lower latitudes. This segregation might partially explain the higher importance attributed to photodegradation in arid conditions.

A particularly contentious subject in photobiology is how best to manipulate the solar spectrum ( Online Resource 7). In photodegradation studies, there is no standard method of filtering solar radiation and this makes it hard to compare multiple studies using different methods which create different microenvironments and exclude different classes of decomposers from reaching the litter, consequently altering the decomposition rates (King et al., 2012). Agreement on a standard method for the manipulation of solar radiation in photodegradation studies would allow a better comparison between them. Of course, the employment of attenuating filters to selectively exclude spectral wavebands and shading treatments also cause a difference in the microclimate to which litter is exposed. Unfortunately, filters almost inevitably modify moisture and temperature, and affect diurnal environmental fluctuations, which are even harder to control in field experiments than in laboratory conditions. A recent assessment found $\mathrm{C}$ loss through thermal emission to be a relatively minor loss pathway compared to photolysis (Day et al., 2019), although the interaction of temperature with biotic processes may still significantly impact our results.

In our analysis, we did not consider potential interactive effects of wavebands combinations, as our aim was to evaluate the impact of specific wavebands on decomposition across different ecosystems and climates. However, when interpreting the results of this meta-analysis, the reader should keep in mind that in a natural environment there is not a clear separation between spectral regions and interactive effects can occur.

\section{Conclusion}

We performed a meta-analysis to test the impact on litter mass loss across published experimental studies that attenuated spectral regions of sunlight considered biologically active in photodegradation. Our results confirmed the importance of sunlight as an abiotic driver of litter decomposition through the process of photodegradation at the global scale. The full spectrum of sunlight increased litter mass loss by $15.3 \% \pm 1 \%$ at the global scale. This implies that photodegradation is an important contributor to the global terrestrial carbon flux. Our meta-analysis scales-up findings from dry and Mediterranean ecosystems that describe the mechanism of photodegradation, to affirm the important role of blue light in litter decomposition globally. This spectral region alone is responsible for an increase in mass loss of $13.8 \% \pm 1 \%$. On the other hand, UV radiation, and its constituents UV-B and UV-A radiation, had no significant effects overall only at a local scale: i.e., these waveband-dependent effects were modulated by climate and ecosystem type. Of covarying abiotic factors, average and maximum temperature positively 
correlated to photodegradation rate. Among initial litter traits, carbon content, lignin content, lignin to nitrogen ratio and SLA all positively correlated with the rate of photodegradation. However, we did not find one common trait that correlated with photodegradation across all the wavebands considered. The role of photodegradation at high latitudes and under tree canopies is at present understudied; more research in these areas will allow us to better define the role of photodegradation across the globe and would represent progress towards estimating its contribution to the global carbon budget.

\section{Declarations}

\section{Funding}

This research was funded by the National Natural Science Foundation of China (32122059), the Chinese Academy of Sciences Young Talents Program, and LiaoNing Revitalization Talents Program (XLYC2007016) to QWW, by Chinese Academy of Sciences President's International Fellowship Initiative (2022VCA0010) and the Japan Society for the Promotion of Science (KAKENHI, 17F17403) to QWW and HK, by Academy of Finland decisions \#266523, \#304519 and \#324555 to TMR, personal EF project and a grant from the Region "Haute-Normandie" through the GRR-TERA SCALE (UFOSE Project) to MP. The authors declare that no funds, grants, or other support were received during the preparation of this manuscript.

\section{Competing Interests}

The authors have no relevant financial or non-financial interests to disclose.

\section{Author Contributions}

QWW and MP formulated the initial idea and designed the study, MP collected the data, QWW and MP analyzed the data. MP wrote the draft of the manuscript and the remaining co-authors revised the manuscript.

\section{Data Availability}

The datasets generated during and/or analysed during the current study are available from the corresponding author on reasonable request.

\section{References}

1. Adair EC, Parton WJ, Grosso D, Silver SJ, Harmon WL, Hall ME, Hart SA, S. C (2008) Simple three-pool model accurately describes patterns of long-term litter decomposition in diverse climates. Glob Change Biol 14(11):2636-2660. doi:10.1111/j.1365-2486.2008.01674.x

2. Aerts R (1997) Climate, Leaf Litter Chemistry and Leaf Litter Decomposition in Terrestrial Ecosystems: A Triangular Relationship. Oikos 79(3):439-449. doi:10.2307/3546886 
3. Almagro M, Maestre FT, Martínez-López J, Valencia E, Rey A (2015) Climate change may reduce litter decomposition while enhancing the contribution of photodegradation in dry perennial Mediterranean grasslands. Soil Biol Biochem 90:214-223. doi:10.1016/j.soilbio.2015.08.006

4. Almagro M, Martínez-López J, Maestre FT, Rey A (2017) The Contribution of Photodegradation to Litter Decomposition in Semiarid Mediterranean Grasslands Depends on its Interaction with Local Humidity Conditions, Litter Quality and Position. Ecosystems 20(3):527-542. doi:10.1007/s10021016-0036-5

5. Aphalo PJ (2018) Exploring temporal and latitudinal variation in the solar spectrum at ground level with the TUV model. UV4Plants Bull 2018(2):45-56

6. Aphalo PJ, Albert A, McLeod A, Heikkilä A, Gómez I, López Figueroa F, Strid Ã (2012) Beyond the visible: a handbook of best practice in plant UV photobiology. University of Helsinki, Division of Plant Biology, Helsinki

7. Assink M, Wibbelink CJ (2016) J. T. Q. M. f. P. Fitting three-level meta-analytic models in R: A step-bystep tutorial. The Quantitative Methods for Psychology, 12(3), 154-174

8. Austin AT, Ballaré CL (2010) Dual role of lignin in plant litter decomposition in terrestrial ecosystems. Proceedings of the National Academy of Sciences, 107(10), 4618. doi:10.1073/pnas.0909396107

9. Austin AT, Méndez MS, Ballaré CL (2016) Photodegradation alleviates the lignin bottleneck for carbon turnover in terrestrial ecosystems. Proceedings of the National Academy of Sciences, 113(16), 4392. doi:10.1073/pnas. 1516157113

10. Bais AF, Lucas RM, Bornman JF, Williamson CE, Sulzberger B, Austin AT, Heikkilä AM (2018) Environmental effects of ozone depletion, UV radiation and interactions with climate change: UNEP Environmental Effects Assessment Panel, update 2017. Photochem Photobiol Sci 17(2):127-179. doi:10.1039/C7PP90043K

11. Baker NR, Allison SD (2015) Ultraviolet photodegradation facilitates microbial litter decomposition in a Mediterranean climate. Ecology 96(7):1994-2003. doi:10.1890/14-1482.1

12. Barnes PW, Throop HL, Archer SR, Breshears DD, McCulley RL, Tobler MA (2015) Sunlight and SoilLitter Mixing: Drivers of Litter Decomposition in Drylands. In: Lüttge U, Beyschlag W (eds) Progress in Botany: Vol. 76. Springer International Publishing, Cham, pp 273-302

13. Beck HE, Zimmermann NE, McVicar TR, Vergopolan N, Berg A, Wood EF (2018) Present and future Köppen-Geiger climate classification maps at 1-km resolution. Sci data 5:180214

14. Bond-Lamberty B, Thomson AM (2010) A Global Database of Soil Respiration Data. Biogeosciences 7:1915-1926. doi:10.5194/bg-7-1915-2010

15. Brandt LA, Bohnet C, King JY (2009) Photochemically induced carbon dioxide production as a mechanism for carbon loss from plant litter in arid ecosystems. J Geophys Research: Biogeosciences 114(G2). doi:10.1029/2008JG000772

16. Brandt LA, King JY, Hobbie SE, Milchunas DG, Sinsabaugh RL (2010) The Role of Photodegradation in Surface Litter Decomposition Across a Grassland Ecosystem Precipitation Gradient. Ecosystems 13(5):765-781. doi:10.1007/s10021-010-9353-2 
17. Brandt LA, King JY, Milchunas DG (2007) Effects of ultraviolet radiation on litter decomposition depend on precipitation and litter chemistry in a shortgrass steppe ecosystem. Glob Change Biol 13(10):2193-2205. doi:10.1111/j.1365-2486.2007.01428.x

18. Bravo-Oviedo A, Ruiz-Peinado R, Onrubia R, del Río M (2017) Thinning alters the early-decomposition rate and nutrient immobilization-release pattern of foliar litter in Mediterranean oak-pine mixed stands. For Ecol Manag 391:309-320. doi:https://doi.org/10.1016/j.foreco.2017.02.032

19. Caldwell MM, Flint SD (1994) Stratospheric ozone reduction, solar UV-B radiation and terrestrial ecosystems. Clim Change 28(4):375-394. doi:10.1007/bf01104080

20. Cheung MWL (2014) Modeling dependent effect sizes with three-level meta-analyses: A structural equation modeling approach. Psychol Methods 19(2):211-229. doi:10.1037/a0032968

21. Day TA, Bliss MS (2019) A spectral weighting function for abiotic photodegradation based on photochemical emission of $\mathrm{CO} 2$ from leaf litter in sunlight. Biogeochemistry 146(2):173-190. doi:10.1007/s10533-019-00616-y

22. Day TA, Bliss MS, Placek SK, Tomes AR, Guénon R (2019) Thermal abiotic emission of CO2 and CH4 from leaf litter and its significance in a photodegradation assessment. Ecosphere 10(5):e02745. doi:10.1002/ecs2.2745

23. Day TA, Bliss MS, Tomes AR, Ruhland CT, Guénon R (2018) Desert leaf litter decay: Coupling of microbial respiration, water-soluble fractions and photodegradation. Glob Change Biol 24(11):54545470. doi:10.1111/gcb. 14438

24. Day TA, Guénon R, Ruhland CT (2015) Photodegradation of plant litter in the Sonoran Desert varies by litter type and age. Soil Biol Biochem 89:109-122. doi:https://doi.org/10.1016/j.soilbio.2015.06.029

25. Day TA, Zhang ET, Ruhland CT (2007) Exposure to solar UV-B radiation accelerates mass and lignin loss of Larrea tridentata litter in the Sonoran Desert. Plant Ecol 193(2):185-194. doi:10.1007/s11258-006-9257-6

26. Egger M, Smith GD, Schneider M, Minder C (1997) Bias in meta-analysis detected by a simple, graphical test. BMJ 315(7109):629. doi:10.1136/bmj.315.7109.629

27. Foereid B, Rivero MJ, Primo O, Ortiz I (2011) Modelling photodegradation in the global carbon cycle. Soil Biol Biochem 43(6):1383-1386. doi:https://doi.org/10.1016/j.soilbio.2011.03.004

28. Gallo ME, Porras-Alfaro A, Odenbach KJ, Sinsabaugh RL (2009) Photoacceleration of plant litter decomposition in an arid environment. Soil Biol Biochem 41(7):1433-1441. doi:https://doi.org/10.1016/j.soilbio.2009.03.025

29. Gallo ME, Sinsabaugh RL, Cabaniss SE (2006) The role of ultraviolet radiation in litter decomposition in arid ecosystems. Appl Soil Ecol 34(1):82-91. doi:https://doi.org/10.1016/j.apsoil.2005.12.006

30. García-Palacios P, Maestre FT, Kattge J, Wall DH (2013) Climate and litter quality differently modulate the effects of soil fauna on litter decomposition across biomes. Ecol Lett 16(8):10451053. doi:https://doi.org/10.1111/ele.12137 
31. Gliksman D, Rey A, Seligmann R, Dumbur R, Sperling O, Navon Y, Grünzweig JM (2017) Biotic degradation at night, abiotic degradation at day: positive feedbacks on litter decomposition in drylands. Glob Change Biol 23(4):1564-1574. doi:https://doi.org/10.1111/gcb.13465

32. Grifoni D, Zipoli G, Viti M, Sabatini F (2008) Latitudinal and seasonal distribution of biologically effective UV radiation affecting human health and plant growth. Paper presented at the Proceedings of 18th International Congress of Biometeorology, 22-26 September 2008, Tokyo, Japan

33. Henry HAL, Brizgys K, Field CB (2008) Litter Decomposition in a California Annual Grassland: Interactions Between Photodegradation and Litter Layer Thickness. Ecosystems 11(4):545-554. doi:10.1007/s10021-008-9141-4

34. Jones AG, Bussell J, Winters A, Scullion J, Gwynn-Jones D (2016) The functional quality of decomposing litter outputs from an Arctic plant community is affected by long-term exposure to enhanced UV-B. Ecol Ind 60:8-17. doi:https://doi.org/10.1016/j.ecolind.2015.05.052

35. King JY, Brandt LA, Adair EC (2012) Shedding light on plant litter decomposition: advances, implications and new directions in understanding the role of photodegradation. Biogeochemistry 111(1):57-81. doi:10.1007/s10533-012-9737-9

36. Knapp G, Hartung J (2003) Improved tests for a random effects meta-regression with a single covariate. Stat Med 22(17):2693-2710. doi:10.1002/sim.1482

37. Lin Y, Scarlett RD, King JY (2015) Effects of UV photodegradation on subsequent microbial decomposition of Bromus diandrus litter. Plant Soil 395(1):263-271. doi:10.1007/s11104-015-25510

38. Ma Z, Yang W, Wu F, Tan B (2017) Effects of light intensity on litter decomposition in a subtropical region. Ecosphere 8(4):e01770. doi:10.1002/ecs2.1770

39. Maestre FT, Escolar C, de Guevara ML, Quero JL, Lázaro R, Delgado-Baquerizo M, Gallardo A (2013) Changes in biocrust cover drive carbon cycle responses to climate change in drylands. Glob Change Biol 19(12):3835-3847. doi:https://doi.org/10.1111/gcb.12306

40. Mao B, Zhao L, Zhao Q, Zeng D (2018) Effects of ultraviolet (UV) radiation and litter layer thickness on litter decomposition of two tree species in a semi-arid site of Northeast China. J Arid Land 10(3):416-428. doi:10.1007/s40333-018-0054-6

41. Meentemeyer V (1978) Macroclimate and lignin control of litter decomposition rates. Ecology 59(3):465-472

42. Méndez MS, Martinez ML, Araujo PI, Austin AT (2019) Solar radiation exposure accelerates decomposition and biotic activity in surface litter but not soil in a semiarid woodland ecosystem in Patagonia, Argentina. Plant Soil. doi:10.1007/s11104-019-04325-1

43. Moody SA, Newsham KK, Ayres PG, Paul ND (1999) Variation in the responses of litter and phylloplane fungi to UV-B radiation (290-315 nm). Mycol Res 103(11):1469-1477. doi:10.1017/S0953756299008783

44. Moody SA, Paul ND, Björn LO, Callaghan TV, Lee JA, Manetas Y, Oudejans AMC (2001) The direct effects of UV-B radiation on Betula pubescens litter decomposing at four European field sites. Plant 
Ecol 154(1):27-36. doi:10.1023/A:1012965610170

45. Olson DM, Dinerstein E, Wikramanayake ED, Burgess ND, Powell GV, Underwood EC, Morrison JC (2001) Terrestrial Ecoregions of the World: A New Map of Life on EarthA new global map of terrestrial ecoregions provides an innovative tool for conserving biodiversity. Bioscience 51(11):933938

46. Pan X, Song Y-B, Liu G-F, Hu Y-K, Ye X-H, Cornwell WK, Cornelissen JHC (2015) Functional traits drive the contribution of solar radiation to leaf litter decomposition among multiple arid-zone species. Sci Rep 5(1):13217. doi:10.1038/srep13217

47. Parton W, Silver WL, Burke IC, Grassens L, Harmon ME, Currie WS, Fasth B (2007) Global-scale similarities in nitrogen release patterns during long-term decomposition. Science 315(5810):361364. doi:10.1126/science. 1134853

48. Pieristè M (2020) Light after death: the importance of spectral composition in litter decomposition processes. Unigrafia, Helsinki

49. Pieristè M, Chauvat M, Kotilainen TK, Jones AG, Aubert M, Robson MT, Forey E (2019) Solar UV-A radiation and blue light enhance tree leaf litter decomposition in a temperate forest. Oecologia 191(1):191-203. doi:10.1007/s00442-019-04478-x

50. Pieristè M, Forey E, Lounès-Hadj Sahraoui A, Meglouli H, Laruelle F, Delporte P, Chauvat M (2020) Spectral composition of sunlight affects the microbial functional structure of beech leaf litter during the initial phase of decomposition. Plant Soil 451:515-530

51. Pieristè M, Neimane S, Solanki T, Nybakken L, Jones AG, Forey E, Robson TM (2020) Ultraviolet radiation accelerates photodegradation under controlled conditions but slows the decomposition of senescent leaves from forest stands in southern Finland. Plant Physiol Biochem 146:42-54. doi:https://doi.org/10.1016/j.plaphy.2019.11.005

52. Pieristè MW, Kotilainen Q-W, Forey TK, Chauvat E, Kurokawa M, Robson H, Jones TM (2021) Alan G. Database for the meta-analysis "Meta-analysis of ecological studies attenuating solar radiation illustrates the importance of blue light over ultraviolet radiation in driving photodegradation of litter in terrestrial ecosystems"

53. Pustejovsky JE (2018) Using response ratios for meta-analyzing single-case designs with behavioral outcomes. J Sch Psychol 68:99-112. doi:https://doi.org/10.1016/j.jsp.2018.02.003

54. Rohatgi A (2019) WebPlotDigitizer (Version 4.2). San Francisco, California, USA. Retrieved from https://automeris.io/WebPlotDigitizer

55. Rutledge S, Campbell DI, Baldocchi D, Schipper LA (2010) Photodegradation leads to increased carbon dioxide losses from terrestrial organic matter. Glob Change Biol 16(11):3065-3074. doi:10.1111/j.1365-2486.2009.02149.x

56. Schade GW, Hofmann R-M, Crutzen PJ (1999) CO emissions from degrading plant matter. Tellus B: Chemical and Physical Meteorology 51(5):889-908. doi:10.3402/tellusb.v51i5.16501

57. Song X, Peng C, Jiang H, Zhu Q, Wang W (2013) Direct and Indirect Effects of UV-B Exposure on Litter Decomposition: A Meta-Analysis. PLoS ONE 8(6):e68858. doi:10.1371/journal.pone.0068858 
58. Sparks AH (2018) nasapower: a NASA POWER global meteorology, surface solar energy and climatology data client for $\mathrm{R}$

59. Sparks AH (2020) NASA POWER API Client. Retrieved from https://docs.ropensci.org/nasapower/

60. Van den Noortgate W, López-López JA, Marín-Martínez F, Sánchez-Meca J (2013) Three-level metaanalysis of dependent effect sizes. Behav Res Methods 45(2):576-594. doi:10.3758/s13428-0120261-6

61. Verhoef HA, Verspagen JMH, Zoomer HR (2000) Direct and indirect effects of ultraviolet-B radiation on soil biota, decomposition and nutrient fluxes in dune grassland soil systems. Biol Fertil Soils 31(5):366-371. doi:10.1007/s003749900181

62. Viechtbauer W (2010) Conducting meta-analyses in R with the metafor package. J Stat Softw 36(3):1-48

63. Viechtbauer W (2019) Meta-Analysis Package for R (Version 2.1-0). Retrieved from http://www.metafor-project.org https://github.com/wviechtb/metafor

64. Wang Q-W, Pieristè M, Liu C, Kenta T, Robson TM, Kurokawa H (2021) The contribution of photodegradation to litter decomposition in a temperate forest gap and understorey. New Phytol 229(5):2625-2636. doi:https://doi.org/10.1111/nph.17022

65. Wang Q-W, Robson TM, Pieristè M, Oguro M, Oguchi R, Murai Y, Kurokawa H (2020) Testing trait plasticity over the range of spectral composition of sunlight in forb species differing in shade tolerance. J Ecol 108:1923-1940. doi:10.1111/1365-2745.13384

66. Zaller JG, Caldwell MM, Flint SD, BallarÉ CL, Scopel AL, Sala OE (2009) Solar UVB and warming affect decomposition and earthworms in a fen ecosystem in Tierra del Fuego, Argentina. Glob Change Biol 15(10):2493-2502. doi:10.1111/j.1365-2486.2009.01970.x

67. Zepp RG, Callaghan TV, Erickson DJ (1995) Effects of increased solar ultraviolet radiation on biogeochemical cycles. Ambio 24(3):181-187

\section{Figures}

\section{Figure 1}

Bias representation: number of studies and replicates by a) each spectral region, $b$ ) absolute latitude of the field sites of the studies, c) ecosystem type; d) climatic zone (see ESM Appendix- 5 for more details about the climate classification); e) decay period (months), f) litter habit, g) litter form and $h$ ) biome type. The biomes are: Boreal forests / Taiga (BF); Deserts and xeric shrublands (DXS); Mediterranean Forests, Woodlands and Scrub (MF); Montane grasslands and shrublands (MG); Temperate broadleaf and mixed forests (TB); Temperate grasslands, savannas and shrublands (TG); Tropical and subtropical moist broadleaf forests (TSB). 


\section{Figure 2}

Effects of exclusion of a) the full spectrum, b) blue light, c) UV-A radiation, d) UV-B radiation and e) UV radiation on litter mass loss according to categories of climate, ecosystem, decay period, habit and litter form. Average effect size (log response ratio) and 95\% $\mathrm{Cl}$ are shown. Numbers in parenthesis represent the number of replicates.

\section{Figure 3}

Locations of the experimental sites of the studies considered in the meta-analysis divided according to the WWF biome classification (see Online Resource 6).

\section{Supplementary Files}

This is a list of supplementary files associated with this preprint. Click to download.

- Supplementarylnformation.docx 